\title{
Dynamics of the spirit possession phenomenon in Eastern Tanzania
}

\author{
By MARJA-LIISA SWANTZ
}

The discussion on the spirit possession phenomenon is related in this study to the more general question of the role of religious institutions as part in the development process of a people living in a limited geographical area of a wider national society.

It is assumed that religion, like culture in general, has its specific institutional forms as result of the historical development of a society, but at the same time religion is a force shaping that history. People's cultural resources influence their social and economic development and form a potential creative element in it ${ }^{1}$. Some of the questions to be asked are: "How are specific religious practices related to the dynamics of change in the societies in question? What is the social and religious context in which the spirit possession phenomenon occurs in them? What social and economic relations get their expression in them? To what extent is spirit possession in this case a means of exerting values and creatively overcoming a crisis or conflict which the changing social and economic relations impose on the people?

The established spirit possession cults are here seen as the institutional forms of religious experience. At the same time it becomes evident that there is institutionalization in process as well as deinstitutionalization of spirit possession where it occurs outside established institutional forms.

Institution is taken as a socially shared form of behaviour the significance of which is commonly recognized by those who share it. By the term spirit possession cult is meant a ritual form of spirit possession of a group which is loosely organized and without strict membership.

The context of the study is four ethnic groups in Eastern Tanzania, near the coast of the Indian Ocean. The data is drawn from the writer's field

${ }^{1}$ Cf. Swantz, Marja-Liisa, 351. 
research and from research which is at present undertaken by a team of Finnish and Tanzanian researchers in Bagamoyo District, northwest of Dar es Salaam. The three year research project is sponsored by the Academy of Finland and is carried out as part of the research programme of the Ministry of National Culture and Youth of Tanzania Government. The general theme of the project is The Role of Culture in the Restructuring of Tanzanian Rural Areas. The restructuring refers to a villagisation programme carried out in the whole country. People are being moved from their scattered homesteads to new villages and old villages are enlarged by incorporating several villages into one. People are going through a process of fundamental social change.

The ethnic groups living in the area are the Zaramo, Kwere, Zigua and Baraguyu-Maasai. The Zaramo, Kwere and Zigua are agricultural Bantuspeaking people, culturally and linguistically closely related to each other, whereas the Baraguyu-Maasai are non-Bantu pastoralists who during over a 40-year period have gradually moved to the area from the interior. In moving closer to the Coast they have come in contact with the coastal agriculturalists and have been exposed to cultural and social patterns different from their own.

One of the new cultural phenomena which the inmoving groups as well as the researchers have come across frequently is so called spirit possession. It occurs either in established ritual occasions as part of therapeutic procedure or as a sudden state that comes upon an individual in his everyday life. In the former case it is here considered to be part of an institutional form of behaviour, in the latter it becomes separated from its institutional use and gains independence which makes possible its dynamic use. I. Lewis uses expressions controlled-uncontrolled or solicited-unsolicited spirit possession ${ }^{2}$.

By spirit possession is meant a phenomenon which occurs as a state of dissociation, here referred to as a trance. The people who experience it interpret it as an evidence of spirit-interference in their lives, culminating in a state of spirit-possession, the trance. This intervention of spirits is most commonly manifested first in an illness or other physical disorder which is interpreted, usually by a diviner, to have been caused by a particular named spirit. Trance is then induced ritually as part of a cure or remedy. If trance

${ }^{2}$ Cf. Lewis, 55. 
is the first expression of the spirit interference suddenly seizing a person, he/she can temporarily be restored to his/her normal condition; but eventually he/she will also require ritual treatment.

The Swahili expression for possession is 'domination', kutawala. It is said that the spirit takes hold of the person, 'kumshika'. The redressive ritual which follows is called 'kupunga pepo', 'to fan the spirits', literally 'the winds'. Exorcism is not the right expression since kupung a means more exact by 'refreshing', perhaps even 'revitalizing'. I. Lewis uses the expressions 'taming, domesticating' in similar contexts, rather than exorcising which would indicate driving the spirit out ${ }^{3}$. The Zaramo and Zigua spiritpractitioners say they raise the spirit to the head of the patient, "kupandisha pepo kichwani'. The patient is given a chiefly insignia of a turban and a flywhisk or a ceremonial axe as a sign that the spirit has been raised to her/his head and is now ruling, dominating the patient. The spirit is then entertained, given a joyful celebration, in the company of other surrounding people who in some of the rituals (madogoli, kilinge) ${ }^{4}$ at this point join the dancing patient. The ritual may last a night and a day or in some types of ritual is continued from night to night over a period of time. At the end the spirit is driven back to its dwelling place in a tree or a pond and leaves the patient temporarily. The bond that has thus been established will have to be continued. The patient is given some sign of belonging to a cult group of a particular spirit.

The discussion of spirit possession phenomenon relates here to the question of change. Examples are readily found which show that the phenomenon is spreading and the practices related to it, just as the belief structures of the people whom it is affecting, are also changing.

The people on the coast of Tanzania have been subject to changes during the last hundred years or more of their history. They have been in interaction with many ethnic groups coming to the coast as porters, slaves, traders or labourers, all dislocated people whose lives had been affected by the more or less forcible intrusion of foreigners, Arabs, Indians and Europeans. All these peoples are represented among the spirits appearing in the spirit possession cults of the coastal ethnic groups; the reverse is the case when the coastal cults have spread inland.

\footnotetext{
${ }^{3}$ Cf. ib., 30.

${ }^{4}$ Cf. Swantz, Marja-Liisa, 190.
} 
It is evident from the complexity and the well established patterns of the possession cults and the diverse roles related to them among the Zaramo and the Zigua that these are long-standing practices there ${ }^{5}$. Among the Kwere the possession exorcism has been worked into a divining cult under the influences from the neighbouring groups. The Kwere readily recognize these aspects as rather recent innovations. The introduction of drums into Kwere rituals is one of the concrete pieces of evidence of the direction from which the influences have come, since the Kwere themselves did not use drums previously.

In the Kwere society rain and agricultural rituals, or redressive rituals in the case of common epidemics, have been performed communally on a village basis until this decade. There are shrines which are preserved for the communal rituals and individual cases are not brought for treatment at these shrines. Among the Zaramo the same shrine is used at a spirit possession cult for individual treatment. This is related to the fact that through dispersion and movements of family units communal rituals have been discontinued. The former types of shrines have been utilized in spirit possession rituals and thus been applied in new contexts for individual purposes. Through healing rites shrines have served both as localised focii of small family or neighbour groups and thus centres of social gatherings. In this way spirit possession cults have facilitated the transfer of elements from former communal rites and ritual places into new contexts. Possession which in an earlier context was a privilege of a few diviners has become an occurrence among large numbers of group members under the influence of other ethnic groups, among whom the possession had already developed into a cult practice earlier. This means that ritual institutions have elements which facilitate adaptation to new conditions and new social contexts. In spirit possession ritual the possession state is institutionally controlled within the ritual, but at the same time has a component of unexpected behaviour arising from the fact that the control is mediated through the unconscious mind.

The clearest example of process of change in religious structures showing how such a liminal phenomenon as spirit possession accommodates change, is the spreading of trance experience among the Baraguyu-Maasai women. Baraguyu-Maasai men induce trance as part of their social practice. The warriors go into a sudden deep state of trance which is brought about by

${ }^{5}$ Cf. Swantz, Marja-Liisa, $196 \mathrm{ff}$., for descriptions of the cults. 
vigorous dancing. In their belief-system there has been no world of multiple spirits to whom this experience would have been credited. It is spoken of as a state of 'anger' which comes upon some warriors after eating meat mixed with certain herbs. Only some, however, are affected by it each time.

In the last two decades Baraguyu women have been affected by trance states of a different order. To an onlooker these states may not seem entirely different from the men's trances, but the Baraguyu themselves recognize no similarity between the two. Anger is said to come upon men in order that they may be brave. Strength and courage were needed in the past for cattle raids and fights with neighbouring groups. Thus such states would have had no function for women. Furthermore, the age-classes which divide and unite Baraguyu men are not to be found among women. Thus when trance states now are being experienced by women they are seen to belong to another sphere of influence. It is almost an offence against a Baraguyu man to suggest that the women's experience appears to be the same as theirs. Its source and social context are considered to be entirely different.

Statements given both by Baraguyu men and women reveal that Baraguyu women were affected by spirit possession experience when they witnessed them among their new neighbours, especially the Zigua in Handeni area. (Inform. from A. Hurskainen's material and own interviews.) "When I saw a person who was possessed by spirits, for whom the ngoma-dance was arranged, I also got a desire to shout and jump and fall down. Then it became clear to me that I too had a spirit. First I felt stiff in my arms and legs, then I started jumping. Even now I get this spirit from time to time. We play drums and tin canisters. I sing those strange songs and get weel again." (The Baraguyu do not otherwise use any drums at all.) Another woman's husband related: "When she came to a place in which many had a spirit and they were drumming for them and songs of different tribes were sung, even she started to make a noise, falling down and speaking Swahili. Then it was known she had a spirit. It had been that illness which had been troubling her all the time, but it had not been known before." Swahili as the coastal language is not otherwise spoken by Baraguyu women.

That the new trance state is caused by spirits of neighbouring ethnic groups is readily accepted by men and women alike. In this way a new spirit world with a new ritual practice is being introduced into the belief system of the pastoral Baraguyu-Maasai. The former world consisted of 
open grasslands populated by cattle and wild beasts and was watched over by God, Ngai, who lived on the mountain. Some ancestors were communicated with in matters of significance to a whole group. When the Baraguyu-Maasai moved to live closer to other ethnic groups, new relationships had to be managed and channels of communication established. The spiritworld of neighbours had to be contended with in order not to be vulnerable to the attacks of their spirits. Thus trance has been experienced in new situations by new categories of people when they have come in contact with others to whose central religious practice it has belonged ${ }^{6}$.

I. Lewis makes the distinction between peripheral cults and such cults as belong to the central religious system of a society and have moralistic overtones. Spirits striking capriciously Lewis relates to the weak social position of the victims to whom the experience gives a channel for a disguised but an effective protest because through it they can manipulate the dominant group. Especially women's possession is interpreted as being a form of protest against the dominant male. The social function of such a peripheral possession emerges as an oblique aggressive strategy. In the central religious systems, on the other hand, an ecstatic experience can be a mystical idiom used to support and legitimize positions of power and authority in society at large ${ }^{7}$.

Lewis also shows that a two-way process takes place. In some societies a central cult has become a peripheral cult and vice versa.

We can ask to what extent this applies to the described situation. The fact that possession cults on the whole proliferate can well be attributed to the weak position of the coastal societies on the whole whose largely illiterate population lacked the economic power to compete with the modern business sector dominated by Indians, Arabs or European business concerns. (Men were versed in Arabic script but it did not help them in business transactions.) Men became labourers on coconut or cotton plantations or in growing urban centres and were made to pay tax from their earnings. Although in the Zaramo and Zigua societies the possession cults have a central place in their religious belief-system and practice the societies themselves have been marginal in the social and economic structure of the larger

\footnotetext{
${ }^{6}$ Mary Douglas's theory about the close correlation of cosmology and the 'grid' and 'group' of a society is relevant here. Cf. Douglas, Mary, $59 \mathrm{ff}$.

${ }^{7}$ Cf. Lewis, $32 \mathrm{ff}$.
} 
society. Thus it is not sufficient to look at the religious system and evaluate the centrality of possession phenomenon within it. Its occurrence and function and the roles developed within cultgroups can only be analysed in proper perspective when one considers not only the position of women in relation to men but also that of men in relation to their employers or of their society as such in relation to the larger society. It is not possible to do so in detail in this article which only attempts to point to a possible direction of analysis.

In the case of the Baraguyu one will have to ask whether the women's position has become weaker in recent years when the possession phenomenon has become more and more common. The close contact with neighbours is not sufficient to explain it. To my knowledge, the trance experience of the Baraguyu women does not include the kind of overt manipulation of husbands which is common in similar cases for example among town women. We cannot look at the women's position only in relation to men. Even if Baraguyu women usually stay close to their home area, they go out to marketplaces and frequent clinics and hospitals. They carry on illiterate as before and, as before, are married young, living in polygnous marriages. Marriages still last for a life-time.

It is only in relation to other ethnic groups that the Baraguyu women experience the weakness of their position. Whereas men maintain their different cultural identity with pride, walking around with their bead array, with spears and sticks, handling cash freely, holding meetings in their own language and have little feeling of inferiority, women have no such shared experiences which would raise similarly their sense of self-identity and pride. They do not possess the same symbolic and social means to make the best of their particular cultural idiom, so they succumb to the spirits of the neighbours. They also have their magnificient bead ornaments and they handle money freely carrying it folded under an armband, but they lack the solidarity created in the age-group gatherings and common ritual occasions of eating meat, called olpul, that men have. On the other hand, the Zigua and Kwere waganga from which Baraguyu women have sought help have not been slow to discover that interpreting even women's ordinary ailments and difficulties in childbirth as spirit diseases will give them a ready source of cash, since the Baraguyu freely handle their surplus cash from cattlesales. Thus it is obvious that economic considerations play a part in instigating a new belief system and practice among the Baraguyu. 
The important aspect to consider in Baraguyu-Bantu relations is the fact that through the possession experience women establish relationships with women of other ethnic backgrounds. This happens in the Lutheran congregations which have been formed by the Maasai themselves, when their women have found release from possession through baptism. It also happens in spirit-cult sessions in which they have started taking part. This then becomes a form of social intercourse which otherwise would be nonexistent.

In the Zaramo and Zigua societies the possession cults have a central place in their religious belief-system and practice. Those who belong to a cult-group have gone through a possession experience. An adept has to show evidence that he has 'passed through a water' or been 'taken up to a tree' as a special proof of his/her power over spirits in order to qualify for his/her role. This kind of experience is re-enacted in the ritual, but a powerful mganga, healer, must be able to claim to have had such experiences and to have returned to the group through the action of other waganga. A charismatic experience which manifests itself in a trancelike state is a dynamic element in a ritual which incorporates individuals into a cult group but it can also become separated from the existing cult-practices. In a new context the trance experience can be instrumental in creating new ritual forms or be attached to old forms. Thus we can speak about the deinstitutionalization of trance experiences and then again their new institutionalization in new contexts. The latter process is clearly taking place among the Baraguyu-Maasai at present, whereas among the Kwere the new ritual forms have already been established, but can still be traced to their origins.

The Zaramo and Zigua have lived close to alien people on the coast, such as the Swahili who have been strongly influenced by Arabs, and later by Europeans. They have had to contend with the spirits of those who dominated their trade and determined the conditions of their economy and politics. They have adopted spirits of the foreigners into their own practices and adopted new ritual forms. But some capricious jini remain who can be controlled only by men of letters, the Muslim clerics, who thus hold positions of prestige and control. Women and men alike are affected by jini. A well known Zaramo male mganga of madogoli cult who became affected by a coastal jini, causing him to roar out loud in the middle of the night, could only be introduced to the lower degrees of authority in the cult, but 
could not exorcise, since he did not know Arabic and could not read the $\operatorname{Koran}^{8}$.

According to Lewis, men are affected in societies in which spirit possession is part of the central religious experience and not a peripheral fringe phenomenon. In them possession is the precondition for the position of religious authority. It is provoked by the protest against gods and interpreted as an assertion that man is master of his fate ${ }^{9}$. However, the differentiation within the cults and roles performed in them indicate correlation with social stratification in the large society.

Among the Zaramo, women are more often exorcised than men, but men appear in positions of authority more often than women. However, women waganga are very common and can also exercise considerable power and command respect. I have shown elsewhere that women who are affected by possession states do not necessarily belong to the most subordinate categories neither can the position of women among the Zaramo be described as being more deprived than that of women in ethnic societies in which such cults have not spread ${ }^{10}$. An ecstatic inspiration is necessary for a position of religious authority and in societies in which positions of secular authority are limited or non-existent it is important to be able to claim spiritual authority. Possession cults become a means of exercising power in the local situation and a means of establishing hierarchies of authority. Hence among the Zaramo and Zigua possession cults are not only expressions of women's marginality and the manipulation of men, but rather manifest the limited scope awarded to the total local societies within the larger societies of which they are part ${ }^{11}$.

Within the coastal village society, the spiritual practitioners have commanded authority and have used rituals to enhance their authority. Had they had other means of influence they would have used them to a greater extent. There have been some who have managed to establish themselves in business either through fishing, smuggling or transport enterprises. The spiritual practitioners have utilized the competitiveness of trade and made

\footnotetext{
${ }^{8}$ Cf. Swantz, Marja-Liisa, 193, 196, 199 f.

${ }^{9} \mathrm{Cf}$. Lewis, $176 \mathrm{f}$.

${ }^{10} \mathrm{Cf}$. Swantz, Marja-Liisa, $218 \mathrm{ff}$.

11 A comparative example is the position of women in South African Independent Churches. Women play an important leadership role in them in a situation in which the total African society is subdued and restricted in scope.
} 
the businessmen contribute to their own well being. The fear of manipulated jini and witchcraft controlled by the coastal religious leaders has been used by them to accumulate wealth and to invest in local business. Thus the coastal forms of spirit possession cults relating to the foreign spirits have utilized traditional beliefsystems as a mechanism to gain economic and social prestige and domination.

Lewis shows how the ecstatic experience in religious practices can either be a sign of a decline of a formerly central religious practice, or a static religious situation can be enlivened through such inspirations ${ }^{12}$. In either case the phenomenon is related to changes which the society is undergoing.

I have suggested that the ecstatic experience in a ritual forms the dynamic element in it which makes it possible for the cult institutions to change according to the changing social and economic situation. The institutions can change their function and serve groups and individuals who by this means can give expression to their social deprivation or gain positions of authority and power.

From the way trance experience is utilized in new social situations we can draw the conclusion that spirit possession experience and possession cults accommodate change in new interaction situations. Particularly in the new process of villagisation when new categories of people come to live together one can expect such practices to proliferate. They provide one channel into which people can direct their frustrations. Because it involves people in social therapeutic gatherings, it is socially more constructive than accusations of witchcraft which can also increase in such situations. Thus spirit possession ritual is not only a way of ritualizing a psychological experience of frustration, it can also be interpreted as a social form of intercommunication.

Traditional institutions are usually seen as conservative forces in a society. Such institutions can, however, incorporate dynamic elements in them, which are utilized by various categories of people either consciously or unconsciously.

In the interaction of traditional institutions and institutional planned innovations such elements can facilitate creativity which is channelled into ritual forms and thus for a period hold off social disintegration until new planned institutions with new socially integrative elements get more fully

${ }^{12} \mathrm{Cf}$. Lewis, 174. 
established. This is one of the ways traditional cultural elements may serve creatively in the process of planned change. Ecstatic experience can by its nature become inspirational. One can, however, anticipate that for example music and dance could serve the same function and be trajectories of creativity, accommodating transfer to new institutions. In this way, creative cultural forms can serve to transfer to new contexts the inspirational elements utilized by people.

Examples of such use of dance in polyethnic urban situations are described by T. Ranger (beni dance) and J. Mitchell (kalela dance) ${ }^{13}$. A. Shorter has dealt with the significance of spirit possession cults in a process of national unification in Tanzania. The guild which have spread across ethnic borders in central Tanzania have by practising liminal rituals reinforced a sense of community in society at large. So also the modern experiments in collective farming, the school as a self-sufficient community and National Service can utilize means deriving from traditional cultural practices in creating new identity. Shorter suggests that politicians who use the language of traditional kinship, life-crisis ritual or even liminal movements to introduce new institutions are not guilty of exaggeration ${ }^{14}$.

A. Shorter has extended V. Turner's concept of liminal state, communitas, which was brought about through organizationally well established Swezi and Migawo rituals among the Kimbu and Nyamwezi, cults which originate in the Interlacustrine area. These Shorter interprets as catering for the suffering and marginal people and serving as a meeting ground for the structurally inferior and the superior. Here, the levelling effect of a cult practice rather than the differentiation becomes emphasized. This is comparable with the point made earlier that the spirit possession experience accommodates the meeting of people from different backgrounds and thus minimizes the potential economic advantages gained by those who officiate.

Turner himself suggests that liminal movements cut across tribal and national divisions in their initial stages. Such movements occur in societies which are going from one cultural state to another. Turner has in mind millenial movements which may fulfil functions similar to spirit possession cults. Both are phenomena occurring in societies in change ${ }^{15}$.

\footnotetext{
${ }^{13}$ Cf. Ranger, 15 ff.; Mitchell, 20 ff.

${ }^{14} \mathrm{Cf}$. Shorter, $146 \mathrm{ff}$.

$15 \mathrm{Cf}$. Turner, $143 \mathrm{ff}$.
} 
There is a dynamic, dialectical relationship between an old order and the new. The new development cannot be reached without the forces derived from the old. The old cultural forms will change but in the meantime they can serve as instruments in accommodating change. I have shown that dynamic elements from the old institutions are selected and used for creating new institutional forms.

\section{Bibliography}

Douglas, Mary, 1970, Natural Symbols Explorations in Cosmology. London.

Historical, 1972, The Historical Study of African Religion. Ed. by T. Ranger \& J. Kimambo. London.

Lewis, I., 1971, Ecstatic Religion. Harmondsworth.

Mitchell, J., 1956, The Kalela Dance. The Rhodes-Livingstone Papers 27. Manchester.

Ranger, T., 1975, Dance and Society in Eastern Africa, The Beni ngoma. London.

Shorter, A., 1972, Symbolism, Ritual and History: an Examination of the Work of Victor Turner. Historical.

Swantz, Marja-Liisa, 1970, Ritual and Symbol in Transitional Zaramo Society. Studia Missionalia Upsaliensia 16. Diss. Uppsala.

Turner, V., 1969, The Ritual Process, Structure and Anti-Structure. Chicago. 